\title{
THE EFFECTIVENESS OF ORIGAMI ON OVERALL HAND FUNCTION AFTER INJURY: A PILOT CONTROLLED TRIAL
}

Lesley M Wilson MSc, BSc(Hons), DipCOT, CMS, PGCert (TLHE) School of Health Sciences and Social Care, Brunel University, Uxbridge, UK

Paul W Roden BA(Hons), BSc(Hons) School of Health Sciences and Social Care, Brunel University, Uxbridge, UK Yukiyo Taylor BSc(Hons) Community Neuro-Rehabilitation Service, Buckinghamshire Primary Care Trust, Aylesbury, UK Louise Marston BSc(Hons) MSc PhD School of Health Sciences and Social Care, Brunel University, Uxbridge, UK

This pilot study measured the effectiveness of using origami to improve the overall hand function of outpatients attending an NHS hand injury unit. The initiative came from one of the authors who had used origami informally in the clinical setting and observed beneficial effects. These observed effects were tested experimentally. The design was a pilot non-randomised controlled trial with 13 participants. Allocation of the seven control group members was based on patient preference. The experimental group members attended a weekly hour of origami for six weeks, in addition to their conventional rehabilitation. Hand function of all participants was measured using the Jebsen-Taylor Hand Function Test before and after the six-week period, and additional qualitative data were gathered in the form of written evaluations from patients. The quantitative data were analysed using the Mann Whitney $U$ test or Fisher's exact test. Themes were highlighted from the qualitative data.

The results show that there was a greater difference in the total score of the experimental group using the impaired hand between pre- and post-intervention of 11.8 seconds, compared with 4.3 seconds in the control group, but this was not statistically significant at the $5 \%$ level $(p=0.06)$. Additionally, differences in the sub-test scores show a markedly larger improvement in the experimental group. Qualitative data indicate that the experimental group experienced the origami sessions as being enjoyable and beneficial. Further research with a larger sample and randomised group allocation is recommended to verify and expand these preliminary findings.

\section{BACKGROUND}

$T$ he rehabilitation of hand function for people following accident or injury has long been a specialist domain of physiotherapists and occupational therapists within the healthcare team. In particular, because the hand is the main 'tool for doing', occupational therapists have developed hand therapy as an area of expertise within their field. Indeed, the use of purposeful activity is a core premise of occupational therapy (Creek 2003, Mayers 1990, Turner et al 1996) and has been discussed extensively (Chandani and Hill 1990, Chia and Yates 1995). The more creative aspects of activity have traditionally been closely related to crafts (Holder 2001, Perrin 2001). However, within hand therapy, and reflecting occupational therapy generally, the occupational nature of rehabilitation has moved somewhat to the periphery of treatment programmes in recent decades, eclipsed by a more biomechanical approach, possibly in response to changed priorities within the health service, but also perhaps due to a general shift away from using creative activities therapeutically within physical settings (Bayliss et al 1983, Barris et al 1986, Rook 1986, Smith 1989, Taylor and Manguno 1991, Drew and Rugg 2001).

This move towards a more explicitly functional approach, incorporating the terms 'therapeutic exercise' and 'purposeful activity', opened up another layer of debate (Dutton 1989, Mills and Fraser 1989, Laseter and Carter 1996, Paquette 1998, Hunt 2001) with views for and against, citing the benefits of both. Anecdotal and conference reports document the motivational aspects of origami (Van der Louw 1992, Gold 1992) and it has been used internationally in therapy by different professionals, including psychologists, doctors, nurses, occupational therapists, art therapists, speech therapists and teachers ( $H O$ 2002). Origami incorporates most of the hand movements that a commonly used treatment medium such as putty exercise does, but without resistance, since most paper folding does not require intensive, repetitive movements. Nevertheless, origami can be very useful for general manual dexterity (Harbin 1971). A detailed activity analysis comparing origami with putty exercise is shown in Appendix 1.

\section{RESEARCH QUESTIONS}

The interest in testing the effectiveness of using origami within hand therapy was taken forward based on the hypothesis that origami would be effective in improving the hand function of people with hand injuries, prompting the formulation of the following research questions:

1. What is the effectiveness of origami compared to conventional hand therapy on overall hand function for people with hand injuries?

2. What are the experiences and perceptions of those people attending the origami sessions?

\section{METHOD}

\section{STUDY DESIGN}

A pilot non-randomised controlled trial was conducted. Hand function of both the control and the experimental group was measured twice, before and after the six week intervention period, and the data from both pre- and post-test 
measurements were compared. Ethical approval was gained from both the University Ethics Committee for Health Sciences and Social Care and the local NHS research ethics committee prior to commencement of the research.

\section{SAMPLE}

32 eligible people with a hand injury or impairment were identified by the head therapist from the overall caseload of existing outpatients at the hand injury unit of a London hospital, according to the following inclusion and exclusion criteria. Inclusion criteria:

1. Patients without significant functional problems in the unaffected hand

2. Patients able to achieve opposition between thumb and at least one finger tip of the affected hand

3. Patients who were expected to attend hand rehabilitation for a minimum of six weeks after the origami sessions started.

Exclusion criteria:

1. Patients with cognitive impairment

2. Patients with memory impairment

3. Patients who had rated four or more in any of categories 24 to 28 on the Disabilities of the Arm, Shoulder and Hand (DASH) Outcome Measure ${ }^{1}$

4. Patients under 16 years of age

5. Patients who had difficulty in following verbal instructions in English.

Of the original 32 people who were written to by the main researcher and invited to participate, 14 patients responded and gave their written informed consent to take part in the study. Additionally, the potential participants'

\section{Figure 1: Flow diagram to show recruitment of study participants}

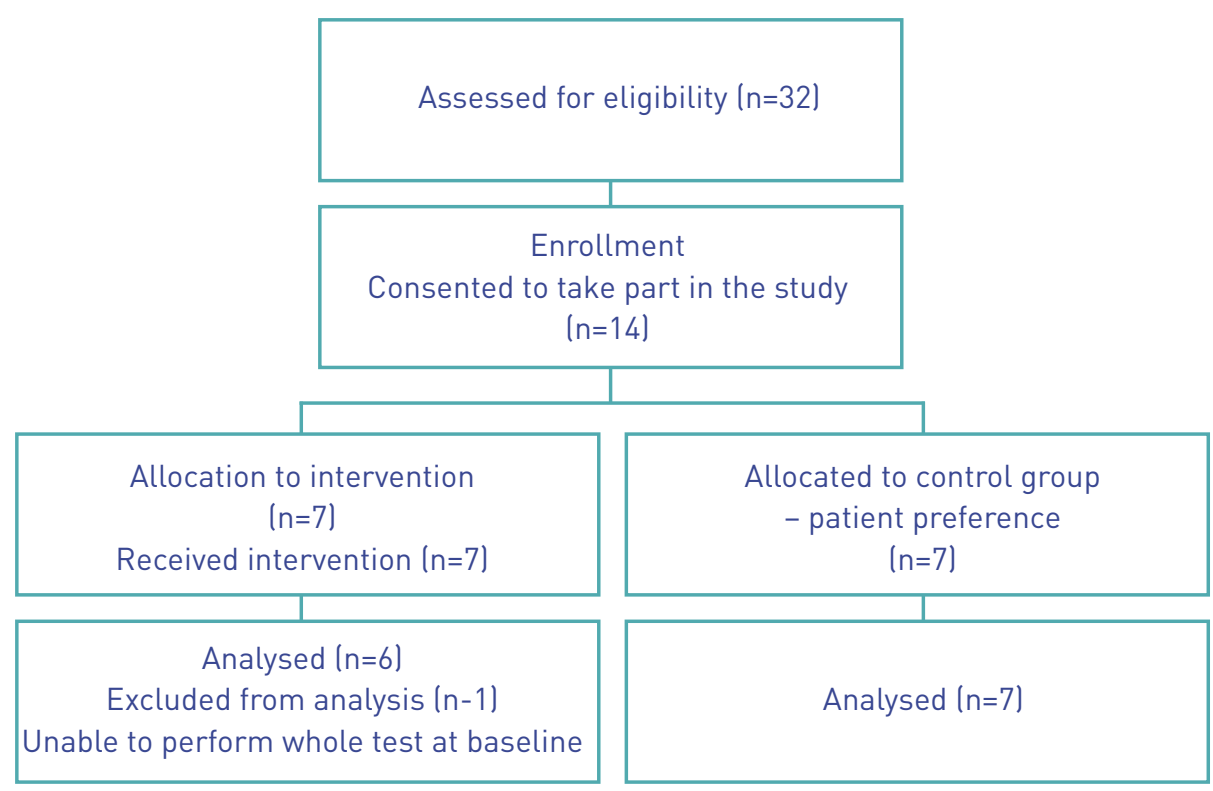

General Practitioner and Consultant were informed of their patient's involvement in the study. Of these 14 volunteers, seven did so only on condition that they would be allocated to the control group, due to constraints on their time. The final assignment of participants to the groups could not therefore be randomised, as had been originally planned. Figure 1 shows the recruitment of study participants. One participant in the experimental group was excluded from analysis because they were unable to perform all subtests of the Jebsen-Taylor Hand Function Test at baseline.

\section{GROUP ALLOCATION}

In order to spread confounding variables such as length of time since injury, type and severity of injury, degree of motivation, lifestyle, age, gender etc it had been anticipated that the participants would be randomly assigned to either the experimental group or to the control group. In the event, allocation to the control group was preference-based, as has already been explained and was therefore not randomised.

Participants were not blinded to whether they were carrying out origami or conventional treatment, mainly because it was a participatory intervention rather than one imposed without knowledge of what was being received. The main researcher taking the measurements and facilitating the origami sessions was not blinded to treatment assignment due to lack of resources and this is acknowledged as being a potential source of bias.

\section{OUTCOME MEASURE}

The Jebsen-Taylor Hand Function Test (Jebsen et al 1969) was selected as an outcome measurement for this study because it is designed to assess the effective use of the hands in everyday tasks. It is composed of seven timed subtests, which provide a broad sampling of hand function, namely the ability to write, turn cards, manipulate small common objects, use a spoon, stack 
draughts, and achieve a wide grasp around both empty and full $1 \mathrm{lb}$ cans. Each subtest has been standardised for a normal population of 30 males and 30 females, both for the dominant and non-dominant hand in five age-groups, from 20 to 94 years (total 300 ) and normative data, together with analysis of variance for age and sex and practice effect, are available (Jebsen et al 1969, Hackel et al 1992). The reliability and lack of significant practice effect over time was considered by the original authors to suggest that this test could provide objective evidence of the possible value of an intervention in improving hand function and it has since been widely used for its good reliability and validity (Jebsen et al 1969, Hackel et al 1992, Hummel et al 2005). Others have studied the stability of the Jebsen-Taylor Hand Function Test (Stern 1992); evaluated it for use with rheumatoid arthritis patients (Sharma et al 1994); the geriatric population (Hardin 2002) and used it as an outcome measure for people with hemiplegia (Spaulding et al 1988, Hummel et al 2005).

In addition to using the outcome measure as described, participants in the experimental group were invited to provide unstructured written responses about their experience and perception of attending the origami group at the end of the last session.

\section{SETTING}

A quiet, bright, clean and comfortable room within the therapy centre at the hospital was used throughout the six weeks of origami sessions. Chairs for the seven experimental participants and the main researcher were arranged around a large table. so that the participants could easily talk to each other. All origami paper and instruction handouts were provided free of charge.

\section{INTERVENTIONS}

In the week prior to the commencement of the origami sessions (week 0 ), hand function of all those who had agreed to participate by giving their informed consent was measured using the Jebsen-Taylor Hand Function Test. Each participant was asked to complete each subtest with the non-dominant hand and then with the dominant hand, and the researcher measured the time they required for each hand with a stopwatch. After six weeks of weekly, one hourly sessions, hand function of all participants from both the experimental and control groups was measured again using the Jebsen-Taylor Hand Function Test (week seven).

The resulting data from the pre-test measurements were used to establish the baseline level of hand function of the participants. The differences in pre- and post-test data were compared for statistical significant differences. Additionally, at the end of the last origami session, participants were invited to provide unstructured written feedback about their experiences during the six weeks of treatment.

\section{Experimental Intervention: Origami} Group

The experimental group attended a one-hour origami session once a week for six consecutive weeks, in addition to their conventional treatment. During the origami session, the participants were frequently reminded of the purpose of the activity and encouraged to use the affected hand as much as possible. Each session had two parts. The first half was used for a long-term project of making a six-layered paper basket, to be completed over six sessions by building up 163 pieces (Mitsuoka 2000). At the end of each session, the participants were given homework to make 24 pieces for the next layer, so that they were able to build the layer when they came for the next session. It was hoped that the homework would familiarise them with paper folding and encourage them to use their hands at home between sessions. In the second half of the session, participants learned to make a range of individual origami models, from simple to more complex ones (Fuse 1998).

\section{Control Group: Conventional Hand} Therapy

The control group members attended once a week for one hour of conventional treatment, which consisted of therapeutic exercises such as using rolling and stretching different consistencies of putty, and board games involving the manipulation of graded grip modalities according to the individual's treatment protocol.

\section{DATA ANALYSIS}

In order to assess the comparability of baseline data between the two groups, and pre-and post-experimental data, statistical analysis for differences was calculated using the Mann Whitney U test or Fisher's exact test as appropriate. Medians and ranges are presented for all continuous variables. Data were analysed using Stata v9 (StataCorp 2005). The outcome is the difference in Jebsen-Taylor Hand Function Test scores between the pre and post intervention groups, measured in seconds.

The responses in the form of open written feedback from the experimental group participants were initially coded according to similar meanings and concepts, and allocated a category as the themes emerged (Robson 2002). Two of the researchers cross-checked 
Table 1: Baseline data

\begin{tabular}{|c|c|c|c|}
\hline VARIABLE & $\begin{array}{l}\text { EXPERIMENTAL GROUP } \\
\qquad(n=6)\end{array}$ & $\begin{array}{l}\text { CONTROL GROUP } \\
\qquad(n=7)\end{array}$ & P-VALUE \\
\hline Age median (range) & $49(34,63)$ & $57(25,81)$ & 0.32 \\
\hline Gender ratio (female:male) & $6: 0$ & $6: 1$ & 1.00 \\
\hline Hand dominance (right:left) & $6: 0$ & 7:0 & $*$ \\
\hline Hand impairment (right:left) & $3: 3$ & $4: 3$ & 1.00 \\
\hline $\begin{array}{l}\text { Baseline score on Jebsen } \\
\text { Test of impaired hand } \\
\text { - seconds median (range) }\end{array}$ & $80.2(51.7,167.8)$ & $54.0(34.3,86.0)$ & 0.12 \\
\hline $\begin{array}{l}\text { Time since injury - months } \\
\text { median (range) }\end{array}$ & $6(2,23)$ & $3(1,11)$ & 0.47 \\
\hline $\begin{array}{l}\text { Length of rehabilitation } \\
\text { - months median (range) }\end{array}$ & $4(0,18)$ & $1(0,3)$ & 0.09 \\
\hline Type of injury & $\begin{array}{c}\text { Fracture }=3 \\
\text { Laceration }=1 \\
\text { Dissociation }=1 \\
\text { Ganglionectomy }=1 \\
\text { Dog bites (mallet finger) }=1\end{array}$ & $\begin{array}{c}\text { Fracture }=6 \\
\text { Ligament injury }=1\end{array}$ & \\
\hline
\end{tabular}

* Impossible to calculate as all participants were right handed.

the thematic codings to enhance the confirmability of the findings (Marshall and Rossman 1995). These are presented with examples and discussed further in the following sections. However, they are only briefly touched upon in this paper, as they warrant more consideration in their own right and form only a small part of the main purpose of this particular pilot study.

\section{RESULTS}

Table 1 gives basic demographic data and the numbers of people allocated to each group. It shows that there were no statistically significant differences in baseline data. However, there was a trend for the time since injury and length of rehabilitation received to be shorter in the control group (median 1 month, range 0 months, 3 months).

The median time taken to complete the Jebsen-Taylor Test at baseline was longer for the experimental group than the control group (80.2 seconds versus 54.0 seconds respectively), although this was not statistically significant ( $p=0.12$ ). Table 2 shows that there was a greater difference in Jebsen-Taylor Hand Function Test score in the experimental group using the impaired hand between pre-and post-intervention. This is more clearly illustrated in Figure 2. Although the difference was notable, for the overall test (sum of the times of the constituent parts), the results did not reach statistical significance at the $5 \%$ level ( $p=0.06)$, with median differences between the two time points of 11.8 seconds and 4.3 seconds for the experimental and control groups respectively. There were no significant differences between the experimental group and control group for the unimpaired hand, nor were there any significant differences in times using left or right hands between groups $(p=0.12$, $\mathrm{p}=0.48$ respectively).

However, for the affected hand, the experimental group consistently made a greater improvement in hand function for each subtest, compared with the control group. In fact, often this was twice or three times as much. The fact that this difference was not statistically significant is hardly surprising given the very small sample size.

\section{QUALITATIVE DATA}

Brief examples of verbatim extracts are given according to the five themes identified from the coded data. The themes were: encouraging use of hands, supportive environment, challenging activity, enjoyable activity and future use of origami. Since this is additional subjective data to supplement that of the objective outcome measure, it gives 
Table 2: Analysis of the Jebsen-Taylor Hand Function Test for impaired and unimpaired hands

\begin{tabular}{|l|c|c|c|c|c|c|}
\hline & \multicolumn{2}{|c|}{ IMPAIRED HAND } & \multicolumn{3}{c|}{ UNIMPAIRED HAND } \\
\hline Variable & $\begin{array}{c}\text { Experimental } \\
\text { group }(n=6)\end{array}$ & $\begin{array}{c}\text { Control group } \\
(n=7) *\end{array}$ & $p$-value & $\begin{array}{c}\text { Experimental } \\
\text { group }(n=6) *\end{array}$ & $\begin{array}{c}\text { Control group } \\
(n=7)^{*}\end{array}$ & $p$-value \\
\hline Writing & $2.4(-2.8,33.8)$ & $0.3(-6.6,2.6)$ & 0.28 & $1.5(-2.4,12.6)$ & $-0.6(-1.7,2.6)$ & 0.32 \\
\hline Page turning & $2.6(-0.2,8.5)$ & $0.9(-0.9,4.5)$ & 0.10 & $0.7(-0.3,1.5)$ & $0.7(-0.2,3.9)$ & 0.72 \\
\hline Picking up small objects & $2.0(0.2,6.8)$ & $0.8(-0.5,1.7)$ & 0.09 & $0.5(0.0,1.8)$ & $0.8(-1.1,1.5)$ & 0.89 \\
\hline Simulated feeding & $2.2(0.5,9.2)$ & $1.5(-0.1,2.3)$ & 0.15 & $1.4(-0.3,2.2)$ & $0.2(-1.2,1.8)$ & 0.31 \\
\hline Stacking draughts & $1.4(0.1,5.2)$ & $0.6(0.2,1.2)$ & 0.35 & $0.4(-0.5,0.7)$ & $0.2(-0.1,1.8)$ & 0.83 \\
\hline Picking up large light objects & $1.0(0.1,4.1)$ & $0.5(-0.7,0.7)$ & 0.25 & $0.9(-0.8,1.3)$ & $0.5(0.0,1.2)$ & 0.57 \\
\hline Picking up large heavy objects & $1.9(0.0,7.3)$ & $0.4(-0.5,2.1)$ & 0.28 & $0.4(-0.7,1.1)$ & $0.1(-0.7,1.4)$ & 0.43 \\
\hline Total & $11.8(1.2,69.2)$ & $4.3(-2.6,9.0)$ & 0.06 & $4.6(-0.2,19.5)$ & $2.6(1.5,5.5)$ & 0.48 \\
\hline
\end{tabular}

*Medians (ranges) are presented for the difference in seconds between pre experiment (baseline) and post experiment

some insights into the experience of the participants.

1. Encouraging use of hands A number of participants commented on how origami encouraged them to use their hands, for instance:

'I was interested and curious to see how this (origamil could help straighten my finger that was injured by a dog-bite, and also help the mobility of my hands. ... I was pleasantly surprised to see that something that seems so simple - just folding paper into shapes - could be so interesting, absorbing and could help fine movements in the hands.

... I have found it to be beneficial as the concentration needed to perform delicate tasks using a damaged finger made me use it in ways I would not normally have done and I have definitely seen the benefit in better movement in the hand.' (E-10)

\section{Supportive environment}

The support of other group members was noted as being beneficial: 'It's very encouraging, and by having people there who have more or less difficulty is a good way of learning from each other. It is mentally very calming and very funny as you can laugh at each other and not be upset, and I think a very valuable healing process.' (E-11)

3. Challenging activity

Not all participants found it easy to carry out the origami sessions: '(I) sometimes found it difficult because of my fingers.' (E-2) 'I found the sessions fun but rather difficult to do.' (E-4)

\section{Enjoyable activity}

The fact that most members of the origami group found the activity enjoyable was reflected in the responses:

'Everyone in the group really enjoyed doing the exercises and I'm sure was very pleased with the outcome.' (E-10)

'Very interesting and enjoyable sessions. ... It is something totally different to what I have done so far in my physio sessions. Very stimulating and interesting.' (E-11)

\section{Future use of origami}

Some of the participants thought that there was a place for origami in
Figure 2: Boxplots to show the difference in Jebson-Taylor Hand Function Test scores before and after intervention for the experimental and control groups

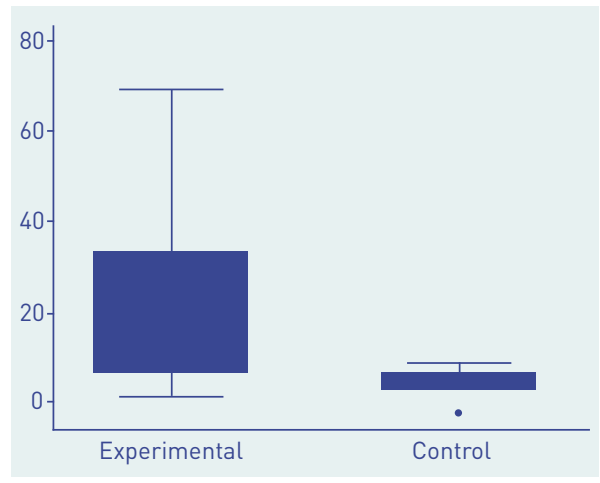

restoring hand function, as evidenced by their comments:

'I think (origami) sessions may well prove to be an asset to hand injury occupational therapy.' (E-4)

'I would love to think that this form of exercise could be used for others to help to regain use of their hands.' (E13)

These five themes give some indication of the added value of attending the origami sessions for those in the experimental group. 


\section{DISCUSSION}

The first research question has been answered although perhaps not as conclusively as would have been hoped. The quantitative results of this study indicate that there was a trend towards origami being beneficial, since there was a larger difference in the Jebsen-Taylor Hand Function Test timings between the experimental and the control group for the impaired hand, particularly when considering the sub-tests separately. This is the most convincing finding of this small pilot study and warrants replication using larger samples. The observed differences failed to attain statistical significance, possibly because of the small sample size and the systematic baseline differences between the experimental and control groups due to non-randomisation of participant allocation. Ideally a larger fully randomised trial would be necessary to confirm whether the trend discovered in these preliminary findings would in fact be sustained with a larger clinical sample. Assuming a mean difference of the total score of 22.33 (SD 25.53) in the experimental group and a mean difference in total score of 4.13 (SD 3.64) in the control group, using $80 \%$ power, a future study would require 16 participants in each of the experimental and control groups lie 32 participants in total). With the same mean and standard deviations, raising the power to $90 \%$ would increase the number of participants needed in each group to 22 (ie 44 in total).

The second research question has been answered by the qualitative data that point to some aspects of the origami sessions that may have contributed to the achievement of positive outcomes as perceived by the participants of the experimental group. Origami seemed to affect not only physical function but also the psychological, emotional and social condition of the participants. Working in a group rather than individually as in traditional treatment sessions was a new form of therapy for all the experimental group participants and is likely to have been therapeutic in itself (Finlay 1993). It was interesting that the experimental group participants made a lot of comments about how they had enjoyed working with others, as well as enjoying the activity itself, as demonstrated in the qualitative data. Their comments particularly highlighted two major benefits of the group sessions: disclosure of difficulties and mutual support. Turner et al (1996) noted that despite the small proportion of total body surface area represented by the hands, the psychological impact of hand injury should not be considered proportionately small. Agreeing with this statement, Moor (1999) suggested that, while the psychological effects of disfigurement to the face are often discussed in the literature, the implications of hand injury for an individual's life can be no less significant. Some experimental group participants told the researcher that they most disliked going shopping, because they felt very embarrassed by their inability to receive change in the palm of the hand. During the origami sessions, the participants felt no need to hide their difficulties from each other. They laughed in a friendly manner at each other's awkwardness and clumsiness in folding paper. They often talked openly about their embarrassing experiences, difficulties and frustration while folding paper.

Kirwan et al (2002) state that compliance is an extremely unpredictable and uncontrollable element of a medical intervention, and can strongly influence the outcome of any treatment. During research on compliance with hand therapy programmes, patients listed the following reasons for non-compliance with the home exercise programme: not enough time, discomfort or pain caused by the programme, the programme's interference with family or social life, and simple forgetfulness. From the experience of the present study, the authors believe that the extent to which patients enjoyed the origami influenced their degree of compliance.

A high attendance rate can be said to demonstrate high compliance and this was the case with the experimental group participants. Furthermore, nobody failed to complete the homework. Whether this level of engagement could be sustained in the long term is a matter for debate.

\section{LIMITATIONS OF THE STUDY}

Limitations of the study need to be acknowledged.

Various factors have influenced and limited this study, including the inequality of baseline characteristics, the small sample size, the possibe expectations of the experimental group and the main researcher, as well as the lack of randomisation and blinding of the tester. The speed and quality of recovery from injury may vary depending on a number of variables, including age, possibly gender, type of injury, severity of injury, length of injury, functional status, personality, lifestyle, occupation and rehabilitation received. Even if two groups of people were to be given exactly the same rehabilitation programme, there would be a difference in the extent of their improvement due to the influence of these variables. Under ideal conditions, to determine whether and how one rehabilitation programme works better than another, it is of course important to eliminate as many influencing 
variables as possible. However in a more pragmatic trial such as this one, realistic human variables prevail.

It was interesting to note, for example, that all but one of the control group participants had been referred due to a fracture, whereas the experimental group comprised a range of injured hand conditions.

Since it was not possible to equalise baseline characteristics through randomisation, it was difficult to identify the exact extent to which origami sessions alone might have contributed to the difference in improvement between experimental and control groups. Although the test-retest reliability of the Jebsen-Taylor Hand Function Test used in this study has been verified elsewhere (Jebsen et al 1969, Stern 1992), it is nevertheless dependent on the person doing the testing. Some subtests, such as simulated page turning, stacking draughts and picking up large objects, could sometimes be completed in no longer than five seconds. A tiny difference in timing accuracy - starting and stopping the stopwatch - could possibly affect the result of these sub-tests, although it is thought to have been unlikely in this study. Another factor that might have affected the results was high expectations on the part of both the tester and the experimental group participants at the time of the post-test measurements. A further limitation was that the same person ran the origami sessions and measured the hand function of the participants; a point noted by the Research Ethics Committee. The participants might have made an extra effort to shorten their times during the second round of testing even though the whole process was overseen and closely supervised. Future research would include single-blinding of an assessor, thus separating measurement from intervention.
Because the sample size of the study was relatively small, the outcome for each participant may have had a marked influence on the measurements of the group as a whole. A larger sample size would have provided a stronger statistical basis for drawing clinically relevant conclusions.

\section{CONCLUSION}

The origami sessions can be said to have had some beneficial effects on overall hand function for the participants in this pilot study. One such effect was origami's encouragement of the use of the injured hand, and perceived improved hand function in both injured and non-injured hands. However, in this pilot study, the improvement was not statistically significant. A larger randomised sample size would be needed to test this hypothesis further.

\section{ACKNOWLEDGEMENTS}

A special thanks to all the participants for their willingness to take part in the study and to Jacki Hunt, Head Occupational Therapist, for her invaluable support in facilitating the research. Thanks are also due to the anonymous reviewers for their painstaking comments on previous drafts of this document.

\section{REFERENCES}

Barris R, Cordero J and Chistiansen R (1986). 'Occupational therapists' use of media', American Journal of Occupational Therapy 40(10):679-84.
Bayliss DE, Goble REA, King DJ and Mendez MA (1983). 'Present trends in occupational therapy practice', British Journal of Occupational Therapy 46(8):2169.

Chandani A and Hill C (1990). 'What really is therapeutic activity?', British Journal of Occupational Therapy 53(1):15-8.

Chia WH and Yates P (1995). 'Purposeful activities? What are they?', British Journal of Occupational Therapy 58(2):75-7.

Creek J (2003). Occupational therapy defined as a complex intervention. London, College of Occupational Therapists.

Drew J and Rugg S (2001). 'Activity use in occupational therapy: occupational therapy students' fieldwork experience', British Journal of Occupational Therapy 64(10):479-86.

Dutton R (1989). 'Guidelines for using both activity and practice', American Journal of Occupational Therapy 43(9):57380.

Finlay L (1993). 'Group work in occupational therapy', Stanley Thornes Ltd, Cheltenham,

Fuse T (1998). Simple traditional origami. Tokyo, Japan Publications.

Gold S (1992). 'Origami as a therapeutic tool', Conference of Origami in Education and Therapy (COET'91) 359-362. The British Origami Society, Birmingham.

Hackel ME, Wolfe GA, Bang SM and Canfield JS (1992). Changes in hand function in the aging adult as determined by the Jebsen Test of Hand Function', Physical Therapy 72:373-7.

Hagedorn R (1995). Occupational therapy: perspectives and processes. Churchill Livingstone, London.

Harbin R (1971). Secret of origami: the Japanese art of paper folding. Octopus Books Ltd, London.

Hardin M (2002). 'Assessment of Hand Function and Fine Motor Coordination 
in the Geriatric Population', Topics in Geriatric Rehabilitation 18(2):18-2.7

Ho G (2002). Use of origami in therapy - examples. Origami \& Therapy Web page.www.geocities.com/paper_folding/ p3.html Accessed 24.4.07

Holder V (2001). 'The use of creative activities within occupational therapy', British Journal of Occupational Therapy 64(2):103-5.

Hummel F, Celnik P, Giraux P, Floel A, Wu W-H, Gerloff $C$ and Cohen LG (2005). 'Effects of non-invasive cortical stimulation on skilled motor function in chronic stroke', Brain 128:490-99.

Hunt J (2001). 'Evaluation of a functional treatment programme for patients following fractured distal radius - a pilot study', Unpublished MSc Allied Health (Hand Function). University of Derby.

Institute for Work and Health (2006).

Disabilities of the Arm Shoulder and Hand

(DASH) Outcome Measure. www.dash.iwh. on.ca/conditions.htm Accessed 6.9.07

Jebsen RH, Taylor N, Trieschmann RB, Trotter MJ and Howard LA (1969). AAn Objective and Standardised Test of Hand Function', Archives of Physical Medicine and Rehabilitation 50(6):311-9.

Kirwan $T$, Tooth $L$ and Harkin $C$ (2002). 'Compliance with hand therapy programs: therapists' and patients' perceptions', Journal of Hand Therapy 15(1):31-40.

Laseter GF and Carter PR (1996).

'Management of distal radius fractures', Journal of Hand Therapy 9(2):114-28.

Marshall C and Rossman G (1995). Designing qualitative research. 2 nd ed. Sage, London.

Mayers C (1990). 'A philosophy unique to occupational therapy', British Journal of Occupational Therapy 53(9):379-80.

Mills D and Fraser C (1989). Therapeutic activities for the upper limb. Winslow
Press, 0xon

Mitsuoka I (2000). (Ed) Tanoshii origami shugei (Enjoyable origami handcrafts), Boutique, Tokyo.

Moor C (1999).' A literature review into the psychological effects of traumatic hand injury and its implications for therapy', British Journal of Hand Therapy 4(3):122-5.

Paquette L (1998). 'Incorporating activities into hand therapy practice', OT Practice June 28-31.

Perrin T (2001). 'Don't despise the fluffy bunny: a reflection from practice', British Journal of Occupational Therapy 64(3):12934.

Robson C (2002) Real World Research. Second ed. , Blackwell, Oxford,

Rook JM (1986). 'The use of skills not involving activities as treatment media' (Letter). British Journal of Occupational Therapy 49(4):134.

Sharma S, Schumacher HR Jr and McLellan AT (1994). 'Evaluation of the Jebsen hand function test for use in patients with rheumatoid arthritis', Arthritis Care and Research 7(1):16-9.

Smith S (1989). 'How occupational therapy staff spend their work time', British Journal of Occupational Therapy 52(3):82-7.

Spaulding SJ, McPherson JJ, Strachota E, Kuphai M and Ramponi M (1988). Jebsen Hand Function Test: performance of the uninvolved hand in hemiplegia and of right-handed, right and left hemiplegic persons', Archives of Physical Medicine and Rehabilitation 69(6):419-22.

StataCorp (2005). Stata Statistical Software: Release 9.0 College Station, Stata Corporation, Texas.

Stern EB (1992). 'Stability of the JebsenTaylor Hand Function Test across three test sessions', The American Journal of Occupational Therapy 46(7):647-9.
Taylor E and Manguno J (1991). 'Use of treatment activities in occupational therapy', American Journal of Occupational Therapy 45(4):317-22.

Turner A, Foster M and Johnson SE (Ed.) (1996). Occupational therapy and physical dysfunction: principles, skills and practice. Fourth ed. Churchill Livingstone, London. Van der Louw (1992). 'Origami with elderly people', Conference of Origami in Education and Therapy (COET'91). 359-62. The British Origami Society, Birmingham.

\section{ADDRESS FOR CORRESPONDENCE:}

Lesley Wilson

School of Health Sciences and Social Care

Mary Seacole Building

Brunel University

Uxbridge

Middlesex

UB8 3PH

lesley.wilsonđbrunel.ac.uk

Tel: 01895268779

(c) British Association of Hand Therapy Ltd 
Appendix 1: Activity analysis of origami and putty based on Johnson's activity analysis (Hagedorn 1995:227)

\begin{tabular}{|c|c|c|}
\hline TITLE & ORIGAMI & PUTTY \\
\hline Category & Purposeful activity & Therapeutic exercise \\
\hline Position & \multicolumn{2}{|c|}{ Seated in the chair with knees under the table with putty/origami paper placed on the table within reach of the hand } \\
\hline Movement & $\begin{array}{l}\text { - Pinch/tripod grip } \\
\text { - Opposition } \\
\text { - (Interphalangeal) IP flexion/ extension } \\
\text { - MCP flexion/extension } \\
\text { - Wrist deviation } \\
\text { - Supination/pronation }\end{array}$ & $\begin{array}{l}\text { - Pinch grip } \\
\text { - Opposition } \\
\text { - IP flexion/extension } \\
\text { - MCP flexion/extension } \\
\text { - Wrist deviation } \\
\text { - Supination/pronation } \\
\text { - MCP abduction/adduction } \\
\text { - Grip/grasp strength }\end{array}$ \\
\hline Grading & $\begin{array}{l}\text { - Resistance: by altering hardness of paper used } \\
\text { - Range of motion (ROM): by altering size of paper used } \\
\text { and complexity of origami model chosen } \\
\text { - Co-ordination: by altering thickness and size of paper } \\
\text { used, and complexity of model chosen }\end{array}$ & $\begin{array}{l}\text { - Resistance: by altering hardness and density of } \\
\text { putty used } \\
\text { - ROM: by altering thickness of putty 'sausage' } \\
\text { squeezed }\end{array}$ \\
\hline Sensory & $\begin{array}{l}\text { - Tactile: required for awareness of hardness, thickness } \\
\text { and texture of paper used } \\
\text { - Visual: required for viewing demonstration and hand } \\
\text { movements required to perform the task correctly } \\
\text { - Auditory: required for following verbal instructions } \\
\text { - Olfactory: nil of note } \\
\text { - Gustatory: nil of note }\end{array}$ & $\begin{array}{l}\text { - Tactile: required for awareness of hardness and } \\
\text { - Vensity of putty used } \\
\text { required to perform the task correctly } \\
\text { - Auditory: nil of note } \\
\text { - Olfactory: nil of note } \\
\text { - Gustatory: nil of note }\end{array}$ \\
\hline Cognitive & $\begin{array}{l}\text { - Motivation: can increase desired outcomes and can be } \\
\text { increased by activity } \\
\text { - Leaning (including memory): required for understanding } \\
\text { aims and instructions } \\
\text { - Problem solving: required when stuck and lost } \\
\text { - Logical thinking: required for folding paper step by step } \\
\text { - Communication: required for interacting with the } \\
\text { instructor or/and fellow participants if working in group } \\
\text { - Organisational ability: nil of note }\end{array}$ & $\begin{array}{l}\text { - Motivation: can increase desired outcomes } \\
\text { - Leaning (including memory): required for under } \\
\text { standing aims and instructions } \\
\text { - Problem solving: nil of note } \\
\text { - Logical thinking: nil of note } \\
\text { - Communication: nil of note } \\
\text { - Organisational ability: nil of note }\end{array}$ \\
\hline Perceptual & N/A within hand therapy & \\
\hline Emotional & $\begin{array}{l}\text { - Positive: pleasure, sense of achievement, satisfaction, } \\
\text { and increased self-esteem and confidence } \\
\text { - Negative: frustration }\end{array}$ & $\begin{array}{l}\text { - Positive: satisfaction and increased confidence } \\
\text { - Negative: boredom }\end{array}$ \\
\hline Social & $\begin{array}{l}\text { - Suitable for group session } \\
\text { - Can offer opportunity to share pleasure and possibly } \\
\text { problems } \\
\text { - May cause competition within group }\end{array}$ & $\begin{array}{l}\text { - Can be done in group } \\
\text { - Can offer opportunity of interaction with others } \\
\text { when done in group, but not sharing }\end{array}$ \\
\hline Cultural & $\begin{array}{l}\text { - Should be acceptable to any culture. } \\
\text { - In Japan, some men may consider for women and children } \\
\text { - In the UK, novelty of the activity can offer opportunity of } \\
\text { learning different culture and new skills }\end{array}$ & - Some adults may consider as childish \\
\hline
\end{tabular}

